\title{
Urban Science: A Short Primer
}

\section{Rob Kitchin}

National University of Ireland Maynooth, rob.kitchin@nuim.ie

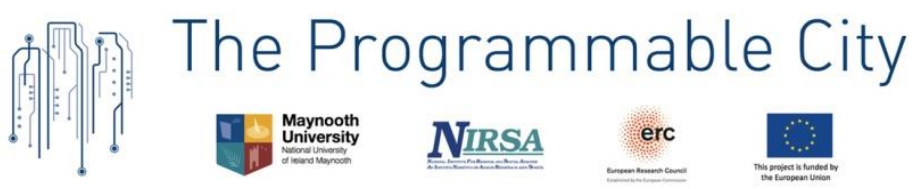

The Programmable City Working Paper 23

http://progcity.maynoothuniversity.ie/

1 February 2017

This paper is an extended version of an essay to be published in Smith, R.G. (ed) The Companion to Urban Studies. Routledge, London.

Published as an open access pre-print on SocArXiv: https://osf.io/preprints/socarxiv/sdsu2

\begin{abstract}
This paper provides a short introductory overview of urban science. It defines urban science, details its practioners and their aims, sets out its relationship to urban informatics and urban studies, and explains its epistemology and the analysis of urban big data. It then summarizes criticism of urban science with respect to epistemology, instrumental rationality, data issues, and ethics. It is concluded that urban science research will continue to grow for the foreseeable future, providing a valuable means of making sense of cities, but that it is unlikely it will become a new paradigm, producing an integrative approach that replaces the diverse philosophical traditions within urban studies.
\end{abstract}

Key words: urban science, urban informatics, urban analytics, urban studies, urban big data, epistemology, critique 


\section{Introducing urban science}

Urban science is an interdisciplinary approach that practices and promotes a scientific and computational explanation of city systems and the processes of urbanization. It uses statistical analysis and data analytics - including machine learning, data mining, visual analytics, modelling and simulation - to identify casual relationships and predict how city systems work. In contrast to urban studies more generally, which views cities as constellations of places with analysis usually based upon fairly static empirical data (small samples, generated at specific places and times), urban science views cities as systems (or a system of systems) with analysis utilising urban big data (massive samples generated on a continuous basis). Typically urban science seeks to map and model urban dynamics patterns of flow, urban processes, and system interactions. The aim is to determine urban 'laws', conduct real-time analysis of systems, produce new theoretical insights, develop a synoptic and integrative science of cities, and to translate the knowledge produced into practical application, including urban design and planning, city management, and economic development.

Urban science builds on a longer history of quantitative social science, including quantitative geography, geographic information science, urban and transportation modelling, social physics, urban and regional economics, urban cybernetics, social ecology, and location theory, that have sought to explain and model urban processes and the functioning of city systems (Batty 2013a). However, many of those now practising and promoting urban science have little grounding in this history, being drawn from data and information science, computer science, physics, and engineering, attracted by the massive volumes of urban big data now being generated, the seemingly intractable problems of cities, and the wider promotion by industry and governments for the creation of so-called 'smart cities' (Townsend 2013; 2015; O'Sullivan and Manson 2013). These drivers have also led to the creation of a number of large, interdisciplinary urban science research centres across the globe (see Batty 2013b; Townsend 2015; and learning resources).

For many of those practising urban science, the approach is promoted as a paradigmshifting endeavour - urban science will provide a more integrative and insightful understanding of cities than urban studies, will transform how urban policy making and planning is undertaken, and will become the dominant approach for urban research. Indeed, Solecki et al. (2013) argue that urban studies has failed to deliver knowledge that effectively solves city issues and is inappropriate for delivering solutions for the major challenges ahead as urbanization continues apace. This unsuitability is due to its disciplinary fragmentation, 
panoply of approaches, and its focus on cities as places and on the symptoms of urban problems. Instead, they call for an urban science that focuses on urban processes and underlying causes (not place and symptoms), draws together theory from the social and natural sciences, and shares a common approach. They propose three basic goals for urban science: (1) to detail the basic components of urbanization across scales; (2) to identify the universal laws of city-building; (3) to find relationships between urbanization and other aspects of Earth's systems. Only urban science they contend can produce 'a theory of urbanization with fundamental and unique components that can withstand scientific scrutiny' and 'lead to systemic solutions that address the whole rather than separate components' (Solecki et al. 2013: 14). Further, because urban science utilises urban big data, it is posited that it offers the potential for urban knowledge that has greater breadth, depth, scale, and timeliness, and is inherently longitudinal, in contrast to that derived from urban studies (Batty et al., 2013).

\section{Relationship to urban informatics}

While Batty (2013b) frames urban science within a larger domain of urban informatics, Townsend (2015) positions urban informatics as sub-branch of urban science, and Kitchin (2016) has them as separate but complementary fields that often intersect. This confusion is due to how urban informatics has been conceived. For Batty (2013b: 3) urban informatics is the 'application of computers to the functioning of cities' and 'the ways in which computers are being embedded into cities'. Here, urban science is one way in which computers are being utilised to understand the functioning of cities and in turn informs how computation is used to manage and control urban systems. For Townsend (2015) and Kitchin (2016) urban informatics is a field concerning the generation, management, processing, analysis and utilisation of urban data. Foth (2009) details that it is an interdisciplinary enterprise that includes three broad communities: social (e.g., media studies, communication studies, cultural studies, sociology); urban (e.g., urban studies, geography, planning, architecture), and the technical (e.g., computer science, data science, electronic engineering, humancomputer interaction). From this perspective, while urban informatics can include research on urban modelling and statistical analysis, it is primarily concerned with the development of informational tools and management systems for controlling and communicating urban processes, understanding human interactions with such systems, and studying the relationship between people, place and digital technology (Foth 2009). Such urban informatics can be informed by urban science, and the urban big data produced by them can provide the 
empirical inputs to urban science research. Many of the new urban research centres detailed by Batty (2013b) and Townsend (2015) conduct both urban science and urban informatics research.

\section{Urban big data}

Along with new computational techniques and data analytics, urban big data are often a vital ingredient of urban science. Such data have fundamentally different properties to traditional 'small' datasets, being generated in real-time, exhaustive in scope, and having fine resolution (Kitchin 2014a). For example, rather than data being derived from a travel survey with a handful of city dwellers during a specific time period at particular locations, transport big data consists of a continual survey of every traveller: for example, collecting all the tap-ins and tap-outs of travel cards, or using automatic number plate recognition-enabled cameras to track all vehicles, or using sensors to monitor the mobile phone MAC addresses to track all pedestrians with a phone. It thus becomes possible to determine detailed patterns of travel across times of the day, days of the week, and seasons, and to do this for all nodes on the network (e.g., junctions, bus stops, sensor locations), and to make predictions about future system performance under different conditions. As a consequence, it is contended, data from such systems have the potential to produce a highly granular, longitudinal, whole system understanding of a city system and enable it to be managed in real-time.

This transformation from slow and sampled data to fast and exhaustive data has been enabled by the roll-out of a raft of new networked, digital technologies embedded into the fabric of urban environments and infrastructures over the past couple of decades. Such technologies include digital cameras, sensors, transponders, meters, actuators, and GPS that monitor various phenomena and continually send data to an array of control and management systems, such as city operating systems, centralised control rooms, intelligent transport systems, logistics management systems, smart energy grids, and building management systems. In addition, a multitude of smartphone apps and sharing economy platforms generate a range of real-time location, movement and activity data. In other words, there has been a radical expansion in the volume, range and granularity of the data being generated about people and places (Kitchin 2014b). The result is a deluge of real-time, fine-grained, contextual and actionable data which are routinely generated about cities and their citizens upon which urban science can be practised (Koonin and Holland 2014). 


\section{Urban science and its epistemologies}

Urban science is broadly rooted in a positivistic tradition that has sought to apply scientific principles and methods, drawn from the natural, hard and computing sciences, to social phenomena in order to explain them. The aim is to statistically test relationships between variables or build models as a means to produce and verify laws that explain and predict how systems work. Central to this endeavour is the objective collection of data through common and standardised methods of observation (that can be replicated) and the formulation of theories which can be tested and verified. In general a realist epistemology is adopted that supposes the existence of an external reality which operates independently of an observer and which can be objectively and accurately measured, tracked, statistically analysed, modelled and visualised to reveal the world as it actually is (Kitchin et al., 2015). In other words, it is held that urban data can be abstracted from the world in neutral, value-free and objective ways and are understood to be essential in nature. That is, data are representative of that which is being measured, faithfully capturing its essence and are independent of the measuring process (though it is acknowledged that there might be data quality issues related to error, bias, calibration, etc.). These data when analysed in similarly objective ways reveal deep insights about cities that can be used to reshape urban policy and enhance urban infrastructures (though it is appreciated that there might be constraints and limitations due to the methodology employed). While cybernetic approaches recognize the complexity and emergent qualities of city systems, such systems are still understood in machinic terms and largely closed and bounded in nature. The production of urban big data and new computational techniques have led to two recent epistemological variations in approach (Kitchin 2014a).

The first is a form of inductive empiricism in which it is argued that by employing data analytics urban big data can speak for themselves free of theory or human bias or framing. Such an approach is best exemplified by Anderson (2008) who argues that 'the data deluge makes the scientific method obsolete' and that '[c]orrelation supersedes causation, and science can advance even without coherent models, unified theories, or really any mechanistic explanation at all.' In other words, rather than being guided by theory, the data can be wrangled through hundreds of algorithms to discover the most salient factors with regards to a particular phenomenon. Such an approach has gained some traction in data science and within industry research. The second is data-driven science that seeks to hold to the tenets of the scientific method, but generate hypotheses and insights 'born from the data' rather than 'born from the theory' (Kelling et al., 2009). It uses guided knowledge discovery techniques to mine data to identify potential hypotheses, before a traditional deductive 
approach is employed to test their validity. This approach is more common because it rejects the idea of the 'end of theory' and maintains scientific values; extracts additional, valuable insights that traditional knowledge-driven science would fail to generate; and it produces more holistic and extensive models and theories of entire complex systems rather than elements of them (Miller 2010; Kelling et al., 2009). In many cases, these approaches have been realised through applied research that uses city environments as 'living laboratories'; that is, as sources of data and as testbeds to validate the science and test the practical interventions produced (see Evans et al. 2016). Indeed, much urban science research is highly empirically grounded and applied in nature, with extensive collaboration between scientists, city administrations and industry partners.

\section{Criticism of urban science}

While urban science has expanded rapidly in the last decade, it is far from producing a paradigmatic shift in urban research and has been subject to critique from urban studies scholars and others. This critique is multi-pronged, with much of it mirroring that of positivistic social sciences and geographic information sciences in previous decades (see Crampton 2010; Kitchin 2015). In these earlier 'theory wars' urban and spatial science were roundly criticised for being too reductionist, mechanistic, essentialist, and deterministic, collapsing diverse individuals and complex, multidimensional social structures and relationships to abstract data points and universal formulae and laws. Moreover, rather than being epistemologically objective, neutral and value-free, it was demonstrated that such science was framed and situated within power-geometries of knowledge and practice and often served particular interests. In addition, they also wilfully ignored the metaphysical aspects of human life and the role of politics, ideology, social structures, capital, and culture in shaping urban relations, governance and development.

Consequently, scientific approaches to cities have been critiqued as being rather naïve and narrow in perspective, producing overly-simplified explanations and models, and a limited and limiting understanding of how cities work (foreclosing what kinds of questions can be asked and how they can be answered) and how urban issues can be tackled. Moreover, they have promoted an instrumental rationality that posits that cities can be effectively steered and managed through scientific insights and technical instruments and that urban issues can be solved through a range of technical solutions (Mattern 2013; Kitchin et al., 2015). Urban science, it is argued, has thus far failed to recognize that cities are complex, multifaceted, contingent, relational systems, full of contestation and wicked problems that are not easily 
captured or steered, and that urban issues are often best solved through political/social solutions, policy interventions, and citizen-centred deliberative democracy rather than technical fixes and technocratic forms of governance (Kitchin et al., 2015). Indeed, critique of the first wave of cybernetic approaches to cities in the later 1960s and 1970s demonstrated that they produced knowledge and policy interventions that not only failed to live up to their promises but did much damage to city operations (Flood 2011; Townsend 2013).

While advocates of computational social and urban science counter that the availability of big data and data analytics address some of the criticisms of earlier forms - especially those of reductionism and universalism by providing more finely grained, sensitive, and nuanced analysis that can take account of context and contingency (Kitchin 2014a) - many concerns undoubtedly still hold for present forms of urban science (Wyly 2014; Kitchin 2016). Moreover, there are other reservations related to urban theory, urban big data and ethical questions. For example, Batty (2013a/b) notes that, despite drawing on complexity theory and advances in data analytics, urban science is still under-powered with respect to providing a detailed explanation of cities and their processes. He argues that there is often a naivety amongst those who do not have a background in urban thinking and policy with respect to framing cities and devising solutions, overly focusing on technology and engineering interventions and failing to heed lessons from the long history of urban policy and planning. As he notes, there are no easy solutions to the intractable problems of cities, and urban science will produce no silver bullets, though that is not to say that it will not produce useful insights. He also cautions against the search for universal laws, arguing that urban systems are too large, complex, fluid, and diverse, instead promoting a more tempered approach of understanding individual systems and recognizing, rather than dismissing, the value in other approaches to understanding cities.

It is also the case that scientific analysis is heavily dependent on data veracity. While urban big data undoubtedly provides numerous opportunities to examine particular systems and issues, they also have a number of limitations. For example, with respect to urban transportation data, while the datasets are rich in volume, they often have limited demographic context (we might know the journeys, but not who took them or why) (Batty 2013b). In many cases, the data are being repurposed having been generated by commercial entities for their specific needs not scientific research. There are thus questions concerning the extent to which repurposed big data provide adequate, rigorous and reliable surrogates for more targeted, sampled data and how representative such data are of phenomena and populations (Struijs et al. 2014). Moreover, big data might seek to be exhaustive, but as with all data they are both a 
representation and a sample. For example, social media data only relate to those who subscribe to a service and are stratified by social class and age, and also include many anonymous and bot accounts. What big data are captured by a system is shaped by: the field of view/sampling frame (where data capture devices are deployed and their settings/parameters); the technology and platform used (different surveys, sensors, lens, textual prompts, and layouts all produce variances and biases in what data are generated); the context in which data are generated (unfolding events mean data are always situated with respect to circumstance); the data ontology employed (how the data are calibrated and classified); and the regulatory environment with respect to privacy, data protection and security (Kitchin 2014a).

Further, much big data have little methodological transparency concerning how they were produced and processed (especially those generated by companies); few metadata with respect to relevance, credibility, timeliness, accessibility, interpretability, coherence, and veracity (accuracy, fidelity, including details of uncertainty, error, bias, reliability, and calibration); and minimal documentation concerning the provenance and lineage of a dataset. And yet it is generally acknowledged that big data can be full of dirty, gamed and faked data, as well as data being absent (Kitchin 2014a). While some might argue that 'more trumps better' and that big data does not need the same standards of data quality, veracity and lineage because the exhaustive nature of the dataset removes sampling biases and compensates for any errors or gaps or inconsistencies in the data (Mayer-Schonberger and Cukier 2013), it is still the case that garbage-data-in produces garbage-analysis-out. Moreover, in many cases, the data are owned by private companies and are not accessible to researchers.

Urban science and its use of urban big data also raises a number of ethical questions that so far have received little consideration. Since much urban big data are exhaustive and indexical, they raise concerns with respect to privacy, dataveillance and geosurveillance, social sorting and anticipatory governance (Kitchin 2016). Big data often record highly detailed patterns of spatial behaviour from which lots of other insights can be inferred (such as mode of travel, activity, lifestyle, co-travellers). The consequence is that individuals are no longer lost in the crowd and it becomes possible to produce and predict detailed individual and place profiles. These profiles can be used to socially sort and redline populations or to socially sort places to receive certain policy interventions. For example, a number of US police forces are now using predictive analytics rooted in urban science research to anticipate 
the location of future crimes and to direct police officers to increase patrols in those areas and to try and identify potential criminals.

Smart city technologies, the data they generate, and the urban analytics applied to them thus have significant direct and indirect impact on people's everyday lives. Few of those whose data has fed into creating predictive profiles imagined that their data were going to be repurposed to social sort or regulate or control them, or nudge them towards certain behaviours. Similarly, some of these data are being used in urban science research for purposes for which they were not intended. Generally, these studies circumvent notice and consent issues, as well as Institutional Research Boards ethics procedures, by anonymizing/aggregating the data. Nonetheless, the research being undertaken can have effects on those who are unwittingly participating by feeding back into the formulation nd delivery of services. In other cases, studies ignore ethical procedures altogether arguing that data in the public domain (e.g., social media data) are open to carte blanche analysis or that they are entitled to experiment on their own systems without user consent (Kitchin 2016).

To address some of these concerns, some have suggested reconceptualising cities within urban science and reframing its epistemology. With respect to the first, rather than being cast as bounded, knowable and manageable systems that can be captured, modelled, steered and controlled in mechanical, linear ways, it is suggested cities need to be understood as fluid, open, complex, multi-level, contingent and relational systems that are full of culture, politics, competing interests and wicked problems (Kitchin 2016). With regards to the latter, it is proposed to shift the epistemology towards those employed in critical GIS and radical statistics. These approaches employ quantitative techniques, inferential statistics, modelling, simulation, visual analytics, etc. whilst being mindful and open with respect to their shortcomings, drawing on critical social theory to frame how the research is conducted, how sense is made of the findings, and the knowledge employed (Kitchin 2014a; Kitchin et al., 2015). Here, it is recognised that there is an inherent politics pervading the datasets analysed, the research conducted, and the interpretations made. Moreover, such a reframing does not foreclose complementing computational social science with 'small data' studies that provide additional and amplifying insights (Crampton et al., 2013). In addition, researchers need to consider the ethical implications of their work with respect to privacy harms and the uses to which their research is being deployed. Beyond complying with relevant laws and institutional IRB requirements, urban science should have a duty of care to citizens not to expose them to harm through its analysis (Kitchin 2016). 


\section{Conclusion}

Building on earlier rounds of quantitative social science and research in the natural sciences, and extending them through the use of new data analytics to extract insights from urban big data, urban science has grown rapidly over the past decade. With the trend in creating smart cities and large-scale investment in urban science research, this growth is likely to continue for some time. It is unlikely, however, that urban science will become a new paradigm, producing an integrative approach that replaces the diverse philosophical traditions within urban studies. This is because urban studies continues to produce useful and insightful research and the inherent weaknesses in the epistemology of urban science. Instead, urban science will provide a complementary approach to urban studies and its epistemology is likely to shift and fracture in the same manner as geographic information science. Nonetheless, it will provide a valuable means of making sense of cities through the analysis of urban big data and contribute significantly to the development of urban policy and planning and the rollout of smart city initiatives.

\section{Acknowledgements}

The research for this paper was funded by an ERC Advanced Investigator award (ERC-2012AdG 323636-SOFTCITY) and a Science Foundation Ireland grant, Building City Dashboards (15/IA/3090). The paper in part draws on Kitchin (2016). Thanks to Claudio Coletta, Paolo Cardullo, Liam Heaphy, and Sung-Yueh Perng for comments on the initial draft.

\section{References}

Anderson, C. (2008) The end of theory: The data deluge makes the scientific method obsolete. Wired, 23rd June. See https://www.wired.com/2008/06/pb-theory/ (last accessed 2 Jan 2017).

Batty, M. (2013a) The New Science of Cities. Cambridge, MA: MIT Press.

Batty, M. (2013b) Urban Informatics and Big Data. London: CASA, University College London. http://www.spatialcomplexity.info/files/2015/07/Urban-Informatics-and-BigData.pdf (last accessed 2 Jan 2017)

Batty, M., Axhausen, K.W., Giannotti, F., Pozdnoukhov, A., Bazzani, A., Wachowicz, M., Ouzounis, G. and Portugali, Y. (2012) Smart cities of the future. European Physical Journal Special Topics 214: 481-518.

Crampton, J.W. (2010) Mapping: A Critical Introduction to Cartography and GIS. Malden, Mass: Wiley-Blackwell. 
Crampton, J.W., Graham, M., Poorthuis, A., Shelton, T., Stephens, M. Wilson, M.W. and Zook, M. (2013) Beyond the Geotag: Situating 'big Data' and leveraging the potential of the geoweb. Cartography and Geographic Information Science 40(2): 130-39.

Evans, J., Karvonen, A. and Raven, R. (eds) (2016) The Experimental City. London: Routledge.

Flood, J. (2011) The Fires: How a Computer Formula, Big Ideas, and the Best of Intentions Burned Down New York City and Determined the Future of Cities. New York: Riverhead. Foth, M. (2009) Preface. In Foth, M. (ed) Handbook of Research on Urban Informatics: The Practice and Promise of the Real-Time City. Hershey, PA: Information Science Reference. pp. xxviii-xxxi

Kelling, S., Hochachka, W., Fink, D., Riedewald, M., Caruana, R., Ballard, G. and Hooker, G. (2009) Data-intensive science: A new paradigm for biodiversity studies. BioScience 59(7), 613-620

Kitchin, R. (2014a) The Data Revolution: Big Data, Open Data, Data Infrastructures and Their Consequences. Sage, London.

Kitchin, R. (2014b) The real-time city? Big data and smart urbanism. GeoJournal 79(1): 1-14. Kitchin, R. (2015) Positivistic geography. In Aitken, S. and Valentine, G. (eds) Approaches to Human Geography, 2nd edition. Sage, London, pp. 23-34.

Kitchin, R. (2016) The ethics of smart cities and urban science. Philosophical Transactions A 374(2083): 1-15.

Kitchin, R., Lauriault, T.P. and McArdle, G. (2015) Knowing and governing cities through urban indicators, city benchmarking \& real-time dashboards. Regional Studies, Regional Science 2: 1-28.

Koonin, S.E. and Holland, M.J. (2013) The value of big data for urban science. In Privacy, Big Data, and the Public Good: Frameworks for Engagement. (pp. 137-152). Cambridge: Cambridge University Press.

Mattern, S. (2013) Methodolatry and the art of measure: The new wave of urban data science. Design Observer: Places. 5 Nov. https://placesjournal.org/article/methodolatry-and-theart-of-measure/ (last accessed 2 Jan 2017)

Mayer-Schonberger, V. and Cukier, K. (2013) Big Data: A Revolution that will Change How We Live, Work and Think. John Murray, London.

Miller, H.J. (2010) The data avalanche is here. Shouldn't we be digging? Journal of Regional Science 50(1), 181-201. 
O'Sullivan, D. and Manson, S.M. (2015) Do physicists have geography envy? And what can geographers learn from it? Annals of the Association of American Geographers 105(4): 704-22.

Solecki, W., Seto, K.C. and Marcotullio, P.J. (2013) It's time for an urbanization science. Environment: Science and Policy for Sustainable Development. 55(1): 12-17.

Struijs, P., Braaksma, B. and Daas, PJH. (2014) Official statistics and big data. Big Data \& Society 1(1): 1-6

Townsend, A. (2013) Smart Cities: Big Data, Civic Hackers, and the Quest for a New Utopia. New York: W.W. Norton \& Co.

Townsend, A. (2015) Making Sense of the New Science of Cities. Rudin Center for Transportation Policy \& Management and Data and Society Research Institute, New York University. http://www.citiesofdata.org/wp-content/uploads/2015/04/Making-Sense-ofthe-New-Science-of-Cities-FINAL-2015.7.7.pdf (last accessed 2 Jan 2017)

Wyly, E. (2014) Automated (post)positivism. Urban Geography 35(5):669-690.

\section{Learning Resources}

To explore examples of urban science research, see the following institute websites:

Centre for Advanced Spatial Analysis, University College London: http://www.bartlett.ucl.ac.uk/casa/research

Senseable City Lab, Massachusetts Institute of Technology: http://senseable.mit.edu/ Center for Urban Science and Progress, New York University: http://cusp.nyu.edu/ Future Cities Lab, ETH Zurich, http://www.fcl.ethz.ch/

Urban Big Data Centre, University of Glasgow: http://ubdc.ac.uk/

Urban Center for Computation and Data, University of Chicago: http://www.urbanccd.org/ Amsterdam Institute for Advanced Metropolitan Solutions: http://www.amsamsterdam.com/home/

To find out more about the relative merits of urban science see the following accessible overviews:

Mattern, S. (2013) Methodolatry and the art of measure: The new wave of urban data science. Design Observer: Places. 5 Nov. https://placesjournal.org/article/methodolatry-and-theart-of-measure/ (last accessed 2 Jan 2017) 
Mehaffy, M. (2014) What Can a 'Science of Cities' Offer Planners? Planetizen. June 25. http://www.planetizen.com/node/69957 (last accessed 2 Jan 2017)

Solecki, W., Seto, K.C. and Marcotullio, P.J. (2013) It's time for an urbanization science. Environment: Science and Policy for Sustainable Development. 55(1): 12-17. http://www.environmentmagazine.org/Archives/Back\%20issues/2013/JanuaryFebruary\%202013/urbanization-full.html (last accessed 2 Jan 2017)

Townsend, A. (2015) Making Sense of the New Science of Cities. Rudin Center for Transportation Policy \& Management and Data and Society Research Institute, New York University. http://www.citiesofdata.org/wp-content/uploads/2015/04/Making-Sense-ofthe-New-Science-of-Cities-FINAL-2015.7.7.pdf (last accessed 2 Jan 2017)

For a nice selection of urban science papers, see:

Batty, M. (ed) (2016) Big data and the city. Special issue of Built Environment 42(3). http://www.alexandrinepress.co.uk/built-environment/big-data-and-city (last accessed 2 Jan 2017)

Ratti, C. and Offenhuber, D. (2014) Decoding the City: How Big Data Can Change Urbanism. Basel: Birkhauser Verlag AG. 